\title{
Lazerle Uzaklık Ölçümü ve Bu Alanda Kullanılan Ölçüm Yöntemlerinin Karşılaştırılması
}

\author{
Şerafettin EREL \\ Ankara Yıldırım Beyazıt Üniversitesi, Mühendislik ve Doğa Bilimleri Fakültesi, Elektrik-Elektronik Mühendisliği \\ Bölümü, 15 Temmuz Şehitleri Binası, Etlik, Ankara, Türkiye
}

\begin{abstract}
Özet:
Lazerler temel özellikleri açısından beyaz ışık kaynaklarına göre önemli farklılıklar gösterirler. Bunlar arasında lazerlerin en temel özelliği monokromatik yapıya sahip olmalarıdır. Bu özellikleri nedeniyle lazerler günlük hayatta önemli uygulama alanları bulmakta olup bu uygulama alanlarından birisi de uzaklık ölçümünde lazerlerin kullanılmasıdır. Lazerle uzaklık ölçümünde "Girişim Ölçme Metodu", "Demet Modülasyon Telemetresi" ve "Atma Eko Teknikleri” olmak üzere üç temel yöntem kullanılmaktadır. $\mathrm{Bu}$ üç farklı yöntemin de birbirlerine göre önemli farklılıkları ve üstünlükleri bulunmaktadır.
\end{abstract}

Anahtar kelimeler: Lazerler, Uzaklık Ölçümü, Monokromatik Işık

\begin{abstract}
:
Lasers show considerable differences in terms of their basic features compared to white light sources. Among them, monochromatic structure is the most basic feature. Because of these features, lasers find important application areas in daily life. One of the application areas of lasers is the use of lasers in distance measurement. Three different methods are used in the laser distance measurement: Interference Measurement Method, Beam Modulation Telemetry and Pulse Echo Techniques. These three different methods have significant differences and advantages over each other.
\end{abstract}

Key words: Lasers, Distance Measurement, Monochromatic Light

\section{Introduction}

Lazerler beyaz 1şık kaynaklarına kıyasla sahip oldukları temel özellikleri [1] nedeniyle günlük hayatta önemli ölçüde kullanım alanları bulmaktadır. Zenginleştirilmiş Yalıtkan Lazerler, Yarıiletken Lazerler, Gaz Lazerleri ve Sivı Boya Lazerleri olarak 4 ana sinıfa ayrılan lazerler sahip oldukları özelliklere göre ayrı önem taşırlar [2]. Lazerler; kesme, delme gibi mühendislik uygulamalarından, diş hekimliğine ve hatta tıpa kadar çok geniş alanda yeni yeni uygulama alanları bulmaktadırlar. $\mathrm{Bu}$ önemli mühendislik uygulamalarından birisi de Lazerle Uzaklık Ölçümü olup bu yöntem sivil ve askeri alanda her geçen gün ayrı bir önem kazanmakta olup bu alanda önemli çalışmalar da yapılmaktadır [3-5]. Özellikle femtosaniyeli atmalı lazerlerle mesafe ölçümünde önemli çalışmaların yapıldığı görülmektedir [6-8]. Lazerle mesafe ölçümü "Girişim Ölçme Metodu, Demet Modülasyon Telemetresi ve Atma Eko Teknikleri” olmak üzere üç temel yöntemle sağlanmaktadır [2].

*Corresponding author: Address: Faculty of Natural Sciences and Engineering, Department of Electrical \& Electronics Engineering Yıldırım Beyazıt University, Etlik, 06010, Ankara, TURKEY. E-mail address: serel@ybu.edu.tr, Phone: +903129062299 


\section{Materyal ve Metod}

Lazerle Uzaklık Ölçümünde kullanılan yöntemlerden birincisi “Girişim Metodu” olup sistem Şekil-1'de görüldüğü gibi sade yapıdadır. Michelson Girişim Ölçeri Girişim Metodu için önemli uygulamadır. Michelson Girişim Ölçeri ile ilgili düzenek Şekil-1'de verilmiştir.

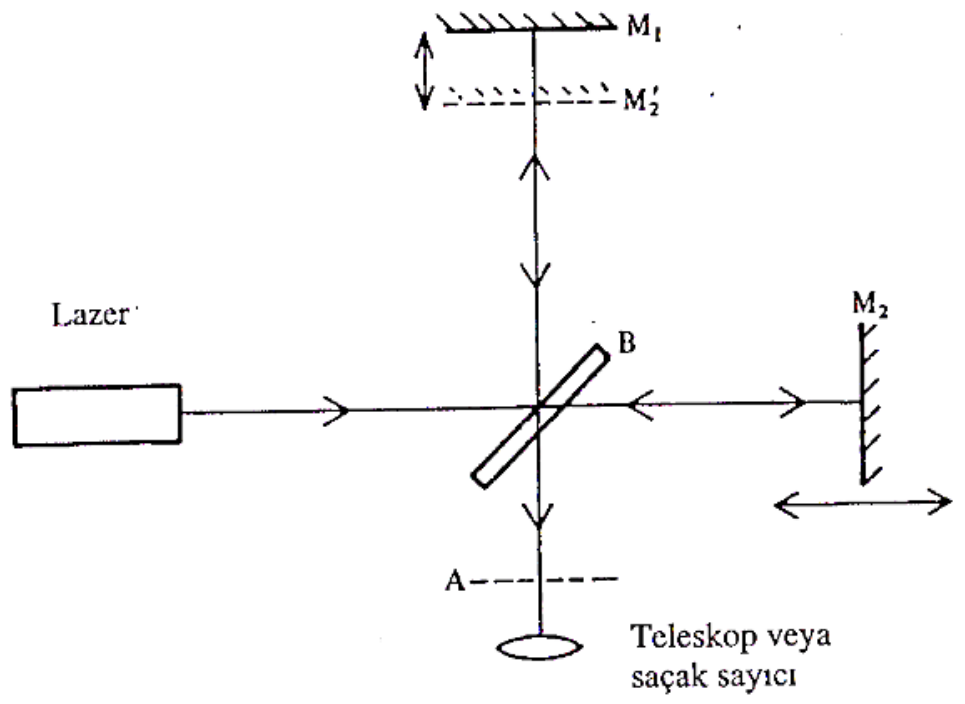

Şekil-1. Michelson Girişim Ölçerinin şematik gösterimi [2].

$\mathrm{Bu}$ tip girişim yöntemlerinde oluşan saçağın görünebilir olması için kullanılan lazer kaynağının da görünür bölgede olması gerekmektedir. Bu nedenle genelde lazer kaynağı olarak He-Ne lazeri kullanılmaktadır. Diğerlerine göre daha ucuz ve daha kolay bulunabilir olması bu alanda He-Ne lazere avantaj sağlamaktadır. Bu yöntemde oluşan saçak sayısı Michelson Girişim Ölçeri için önemli bir parametre olarak değerlendirilir. $670 \mathrm{~nm}$ dalga boyunda 1şıma yapan bir He-Ne lazer kaynağ1 ve sensörü Şekil-2’de görülmektedir.

*Corresponding author: Address: Faculty of Natural Sciences and Engineering, Department of Electrical \& Electronics Engineering Yıldırım Beyazıt University, Etlik, 06010, Ankara, TURKEY. E-mail address: serel@ybu.edu.tr, Phone: +903129062299 


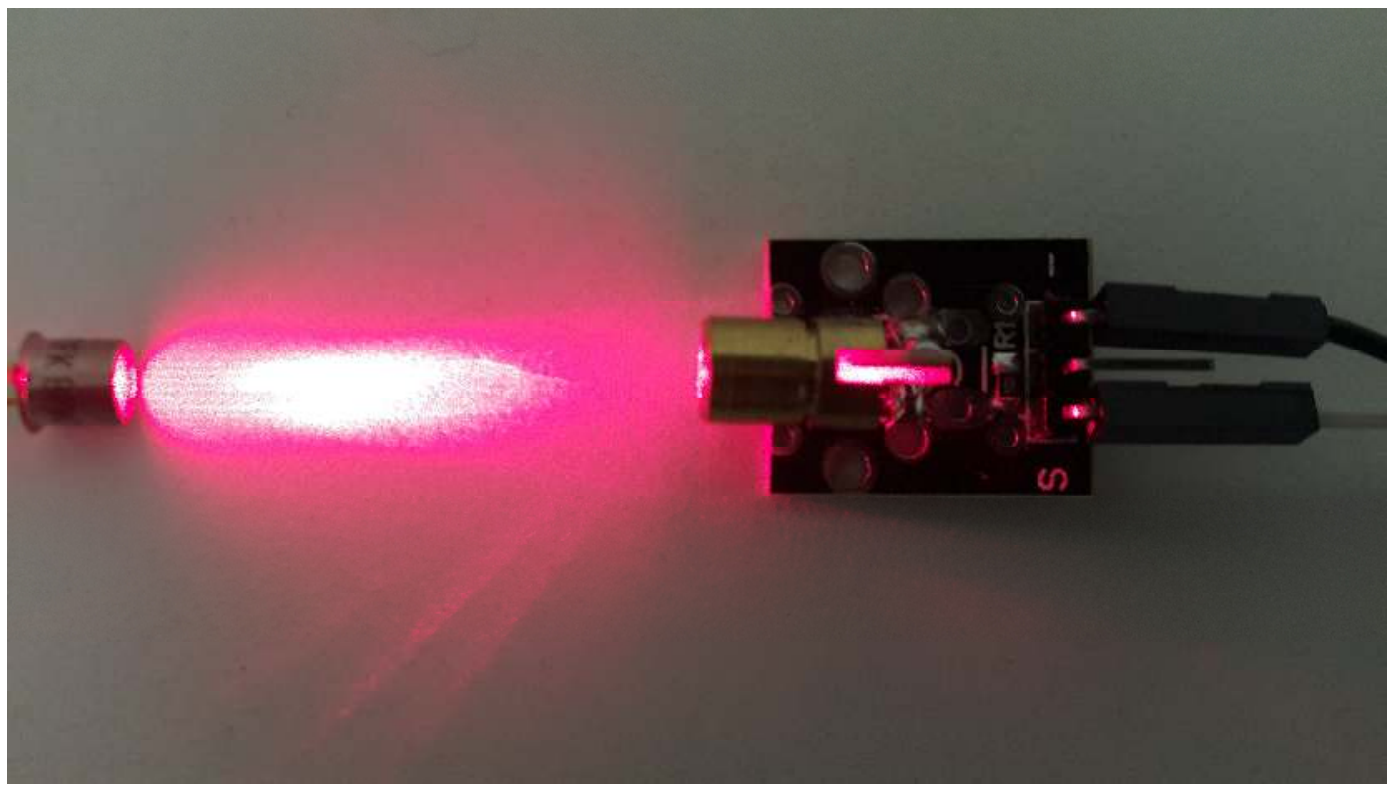

Şekil-2. $670 \mathrm{~nm}$ dalgaboyunda ışıma yapan bir He-Ne lazer kaynağı ve sensörü.

Lazerle uzaklık ölçümünde kullanılan ikinci yöntem ise Demet Modülasyon Telemetrisi olup ilgili düzenek Şekil-3'de görülmektedir.

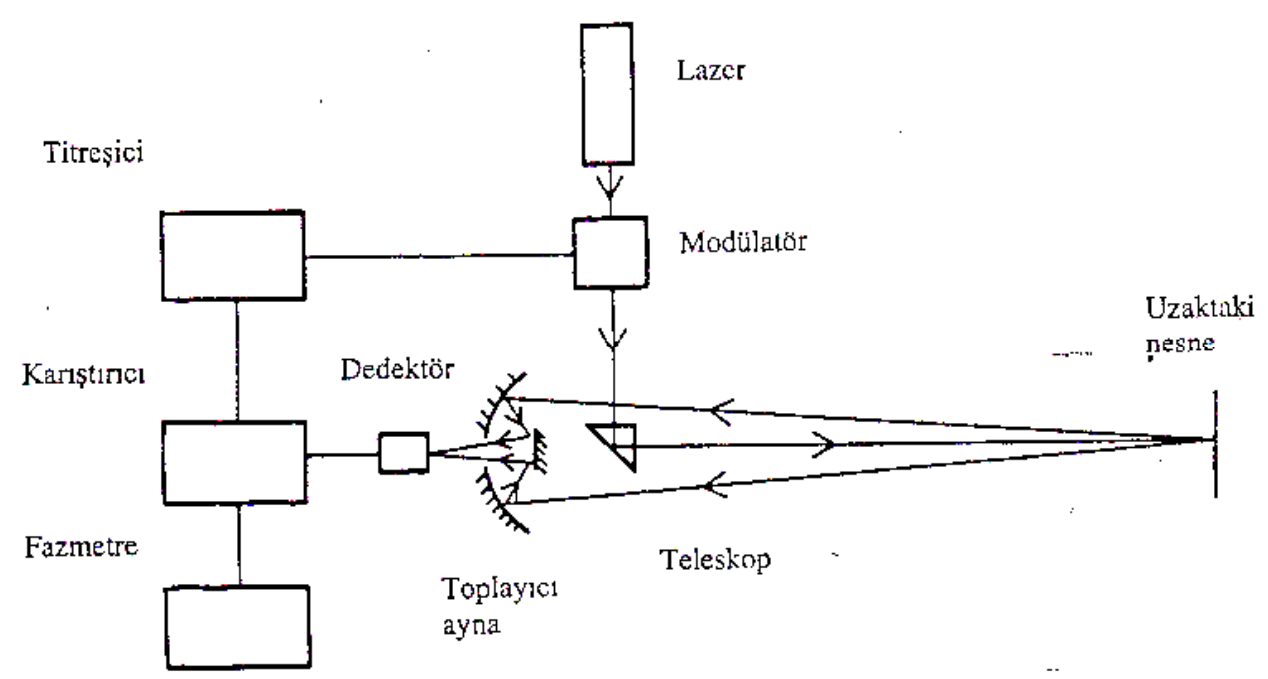

Şekil-3. Demet Modülasyon Tekniğiyle ilgili düzenek [2].

Şekil-3'den de görüldüğü gibi Demet Modülasyon Tekniği, Girişim Metoduna göre daha karmaşık yapıya sahiptir. Bu alanda kullanılan üçüncü teknik ise Atma Eko Tekniği olup bu yöntem daha uzun mesafelerde kullanılmakta olup ölçüm hassasiyeti de oldukça yüksektir. Söz

*Corresponding author: Address: Faculty of Natural Sciences and Engineering, Department of Electrical \& Electronics Engineering Yıldırım Beyazıt University, Etlik, 06010, Ankara, TURKEY. E-mail address: serel@ybu.edu.tr, Phone: +903129062299 
konusu teknikle $10 \mathrm{~km}$ 'lik mesafede \pm 5'lik hata ile ölçüm yapabilmektedir. Ele alınan yöntem genelde Optiksel Radar veya Lidar olarak ta bilinmekte olup bu yöntem atmosferik çalışmalarda da kullanılmaktadır [2]. Özellikle atmosferik çalışmalarla ilgili olarak rüzgarın hızı, yönü, hava kirliliği gibi konularda bu metod oldukça başarılı olup gelişmeye açık bir yöntemdir. Ancak bununla birlikte lazerle mesafe ölçümünün daha hızlı ve daha hassas sonuçları sağlaması açısından da önem çalışmaların yapıldığı görülmektedir [9].

\section{Tartışma}

Lazerle uzaklık ölçümünde kullanılan ve Şekil-1'de verilen Girişim Metodu yapısal olarak incelendiğinde sistem; lazer kaynağı, biri sabit diğeri hareketli olmak üzere iki ayna, teleskop veya saçak sayıcıdan oluşmaktadır. İkinci uzaklık ölçüm yöntemi olup Şekil 3'de verilen Demet Modülasyon Tekniğinde ise; lazer kaynağı, titreştirici, karıştırıcı, fazmetre, detektör, modülatör ve teleskop sistemi bulunmaktadır. Atma Eko Tekniği ise yapısal olarak diğer iki yöntemden de oldukça farklı yapıya sahip olup ele alınan her üç yöntemde de kullanılan lazer kaynağının farklı dalga boyu ve sınıflarda olduğu düşünülmektedir. Lazerle uzaklık ölçümünde kullanılan her üç yöntem kullanılacağı yer ve uzaklığa bağlı olarak önem kazanırlar.

\section{Sonuç}

Lazer 1şını kullanılarak üç temel yöntemle uzaklık ölçümü yapılabilmektedir. Kısa mesafe ölçümü için (en fazla 100 metreye kadar) Girişim Metodu, uzun mesafeler için Demet Modülasyon Tekniği ve çok daha uzun mesafeler için ise (örneğin dünya ile ay arasındaki mesafenin ölçümü gibi) Atma Eko Tekniği en uygun yöntem olarak kullanılmaktadır. Bununla birlikte söz konusu ölçüm tekniğindeki sıralamanın maliyet açısından da benzer bir sıralamada geçerli olabileceği düşünülmektedir.

\section{Kaynaklar}

[1] Quimby RS, Photonics and Lasers, A Wiley-Interscience Publication, John Wiley\&Sons, Inc, New Jersey: 2006

[2] Okur İ, Optoelektronik, Değişim Yayınları. Adapazarı: 20000

[3]Amann MC, Bosch TM, Lescure M, Myllylae RA Rioux M. Laser ranging: a critical review of unusual techniques for distance measurement, Optical Engineering 2001; https: //doi.org/10.1117/1.1330700

[4] Lombardo V, Marzulli T, Pappalettere C, Sforza P, A time-of-scan laser triangulation technique for distance measurements, Optics and Lasers in Engineering, 2003;2:247-254.

[5] Nava E, Stucchi E, Development of lasers for spaceborne Doppler wind lidar applications, Optics and Lasers in Engineering, 2003; 2:255-263.

[6] Joo KN, Kim Y, Kim SW, Distance measurements by combined method based on a femtosecond pulse laser, 2008;16:24: 19799-19806.

*Corresponding author: Address: Faculty of Natural Sciences and Engineering, Department of Electrical \& Electronics Engineering Y1ldırım Beyazıt University, Etlik, 06010, Ankara, TURKEY. E-mail address: serel@ybu.edu.tr, Phone: +903129062299 
[7] Joo KN, Kim SW, Absolute distance measurement by dispersive interferometry using a femtosecond pulse laser, Opt. Express, 2006; 14:13:5954-5960.

[8] Wu H, Zhang F, Cao S, Xing S, Qu X, Absolute distance measurement by intensity detection using a mode-locked femtosecond pulse laser, Opt. Express, 2014; 22:9: 10380-10397.

[9] Zhu Z, Xu G, Ni K, Zhou Q, Wu G, Synthetic-wavelength-based dual-comb interferometry for fast and precise absolute distance measurement, Opt. Express, 2018;26:5: 5747-575

*Corresponding author: Address: Faculty of Natural Sciences and Engineering, Department of Electrical \& Electronics Engineering Y1ldırım Beyazıt University, Etlik, 06010, Ankara, TURKEY. E-mail address: serel@ybu.edu.tr, Phone: +903129062299 